\title{
The influence of malnutrition on the postprandial metabolic rate and respiratory quotient
}

\author{
By O. G. BROOKE AND ANN ASHWORTH \\ Medical Research Council, Tropical Metabolism Research Unit, \\ University of the West Indies, Kingston 7, Jamaica \\ (Received 6 Fuly 1971 - Accepted 2 September 197I)
}

\begin{abstract}
I. Pre- and post-prandial metabolic rates were measured in twelve malnourished Jamaican infants.

2. On admission to hospital, minimal increases in postprandial metabolic rate were found, whereas during the recovery phase when growth was rapid, increases in postprandial metabolic rate of up to $38 \%$ occurred.

3. After recovery only the five children who were still gaining weight at a rate of more than $4 \mathrm{~g} / \mathrm{kg}$ body-weight. $\mathrm{d}$ continued to show a substantial increase in postprandial metabolism.

4. A highly significant correlation was found between growth rate and the increase in postprandial metabolic rate.

5. Marked differences existed in the respiratory quotient measured $4 \mathrm{~h}$ after the last meal, the values being low on admission and high during the phase of rapid growth.

6. After a test meal, the respiratory quotient rose sharply both in newly admitted and in recovered children, but fell slightly when the children were studied during the phase of rapid growth.
\end{abstract}

There have been a number of instances in which experimental evidence has been contrary to the classical theory of specific dynamic action (Coleman \& Dubois, I915; Passmore \& Ritchie, 1957; Miller, Mumford \& Stock, 1967). Children recovering from malnutrition provide yet another example. Krieger (1966) found that, when underweight children were re-fed and were gaining weight rapidly, large increases in postprandial heat production occurred. Previous work undertaken in this Unit (Ashworth, 1969a) showed that postprandial metabolic rates increased substantially in infants recovering from malnutrition, reaching a maximum at $\mathrm{I}-\mathrm{I} \cdot 5 \mathrm{~h}$ after the meal. No such increases occurred in children who had recovered.

In this paper we describe further studies which include measurements of postprandial metabolic rate in malnourished children on admission to hospital, as well as measurements made during rapid growth and after recovery. In order to try to substantiate the hypothesis that in children recovering from malnutrition the increase in metabolic rate after a meal might reflect the energy cost of growth, increases in postprandial metabolic rate have been correlated with rates of growth during and after recovery. In addition, the effect of malnutrition on the pre- and post-prandial respiratory quotient $(\mathrm{RQ})$ is described. 


\section{EXPERIMENT A L}

\section{Subjects and procedure}

Twelve malnourished Jamaican infants were studied on admission to our metabolic ward, and subsequently during the phase of rapid growth and after recovery. All were severely malnourished and their ages ranged from 3 to 20 months. Individual details of the children are given in Table $\mathrm{I}$.

\begin{tabular}{|c|c|c|c|c|}
\hline Child & $\begin{array}{c}\text { Age } \\
\text { (months) }\end{array}$ & $\begin{array}{l}\text { Weight } \\
\text { (kg) }\end{array}$ & $\begin{array}{l}\text { Weight as } \\
\text { a percentage } \\
\text { of expected } \\
\text { weight for } \\
\text { height }\end{array}$ & Oedema \\
\hline E.McL. & 12 & $4 \cdot 4$ & 60 & $\circ$ \\
\hline C.E. & 9 & $5 \cdot 1$ & 70 & 0 \\
\hline P.A. & 7 & $4 \cdot 2$ & 65 & 0 \\
\hline M.D. & 18 & $7 \cdot 2$ & 60 & o \\
\hline D.W. & 20 & $5 \cdot 2$ & 69 & $\circ$ \\
\hline M. M. & I7 & 5.9 & 72 & + \\
\hline R.W. & 8 & $5 \cdot 6$ & 69 & 0 \\
\hline R.S. & 18 & 57 & 62 & 0 \\
\hline S. M. & 8 & 43 & 72 & + \\
\hline E. L. & 3 & $3 \cdot 0$ & 70 & 0 \\
\hline J.A. & 9 & $3 \cdot 2$ & 65 & o \\
\hline Y.B. & 14 & 5.4 & 60 & + \\
\hline Mean & 12 & $4 \cdot 9$ & 66 & \\
\hline
\end{tabular}

Initial studies were made as soon as possible after admission. Studies on recovered children were made either when the child had exceeded his expected weight for height, or when his growth curve had reached a plateau. We use as our standards the 5oth percentile figures for American children (Nelson, Vaughan \& McKay, 1969), from which the expected weight for height can be calculated by plotting a graph of median weight against median height. At least one study was made on each child during the phase of rapid growth.

For the purpose of correlating the increase in postprandial metabolic rate with growth rate, results obtained from studies on a further ten patients have been included.

All children were weighed daily and from these measurements growth rates were calculated for the week preceding each study by fitting a line by the method of least squares.

\section{Dietary regimen and test meals}

On admission the children were given graduated feeds, with potassium, iron and vitamin supplements. As soon as they were feeding well, a high-calorie milk preparation was introduced which provided $1350 \mathrm{kcal}$ and $3 \mathrm{I} \mathrm{g}$ protein per I; the composition was $190 \mathrm{~g}$ dried full-cream milk (a proprietary preparation which incorporates maize starch, dextrin-maltose and sucrose; total carbohydrate $57 \%$, fat $17 \%$, protein $\mathrm{I} 6.5 \%$ ) and $60 \mathrm{~g}$ arachis oil. With this regimen, growth rates of $7-\mathrm{I} 9 \mathrm{~g} / \mathrm{kg}$ bodyweight. $d$ were achieved during the recovery phase and intakes were of the order of I69 $\mathrm{kcal}(7 \cdot \mathrm{IMJ})$ and $3.9 \mathrm{~g}$ protein $/ \mathrm{kg}$ body-weight.d. 
This milk preparation was also used for the test meals and the amount given provided $27 \mathrm{kcal}(\mathrm{Ir} 3 \mathrm{~kJ})$ and $0.7 \mathrm{~g}$ protein $/ \mathrm{kg}$ body-weight per meal.

None of the patients had diarrhoea or fever, nor was any hypothermic. In one patient (M.D.) the initial test meal provoked a diarrhoea stool shortly after the study. No diarrhoea occurred subsequently, or when the study was repeated $2 \mathrm{~d}$ later.

\section{Measurement of metabolic rates}

All studies were performed in the afternoon, starting $4 \mathrm{~h}$ after the previous meal. The children were kept awake in the morning to ensure an adequate period of sleep during the study, and then were lightly sedated with chloral hydrate or rectal paraldehyde. Oxygen consumption and $\mathrm{CO}_{2}$ production were measured with a Kipp and Zonen Noyons diaferometer connected to a metabolism chamber containing the child. From these measurements values for RQ and metabolic rate were derived. Calibration of the diaferometer was checked at regular intervals by the ethanol-burning technique described by Mount (1969), and did not change significantly during the period of the studies. The chamber temperature was maintained within the thermoneutral range throughout.

After the initial 'standard' $4 \mathrm{~h}$ postprandial metabolic rate had bcen determined, the test meal was given through a nasogastric tube and subsequent changes in metabolic rate were followed at 15 min intervals for $1 \cdot 75 \mathrm{~h}$. If the child became restless, the results were abandoned and the study was repeated the next day.

Table 2. Rate of weight gain of the children and corresponding pre- and post-prandial metabolic rates (MR) (call/kg body-weight.min)

(Mean values, with their standard errors, for twelve children)

\begin{tabular}{|c|c|c|c|c|c|c|c|c|c|}
\hline & \multirow{2}{*}{$\begin{array}{l}\text { Mean } \\
\text { growth } \\
\text { rate } \\
\text { (g/ } \\
\mathrm{kg} \cdot \mathrm{d} \text { ) }\end{array}$} & \multirow{2}{*}{$\begin{array}{c}\text { MR } \\
\text { before } \\
\text { meal }\end{array}$} & \multicolumn{7}{|c|}{ MR after meal at time (min): } \\
\hline & & & 15 & 30 & 45 & 60 & 75 & 90 & 105 \\
\hline $\begin{array}{l}\text { On } \\
\text { admission }\end{array}$ & - & $\begin{array}{r}42 \cdot 0 \\
\pm r \cdot 4\end{array}$ & $\begin{array}{r}42 \cdot 8 \\
\pm \mathrm{r} \cdot 9\end{array}$ & $\begin{array}{r}43 \cdot 3 \\
\pm 2 \cdot 2\end{array}$ & $\begin{array}{r}44 \cdot 2 \\
\pm 1 \cdot 6\end{array}$ & $\begin{array}{r}44.9 \\
\pm 1.6\end{array}$ & $\begin{array}{r}44 \cdot 1 \\
\pm 1 \cdot 7\end{array}$ & $\begin{array}{r}43 \cdot 9 \\
\pm 1 \cdot 7\end{array}$ & $\begin{array}{r}43 \cdot 3 \\
\pm I \cdot 6\end{array}$ \\
\hline $\begin{array}{l}\text { During } \\
\text { rapid growth }\end{array}$ & $h^{12 \cdot 6}$ & $\begin{array}{r}45.7 \\
\pm 1.5\end{array}$ & $\begin{array}{r}51 \cdot 4 \\
\pm 2 \cdot 1\end{array}$ & $\begin{array}{r}54 \cdot 1 \\
\pm 2 \cdot 1\end{array}$ & $\begin{array}{r}55.8 \\
\pm I * 9\end{array}$ & $\begin{array}{r}56 \cdot 6 \\
\pm 2 \cdot 0\end{array}$ & $\begin{array}{r}55 \cdot 5 \\
\pm 2 \cdot 0\end{array}$ & $\begin{array}{r}53 \cdot 9 \\
\pm 2 \cdot 2\end{array}$ & $\begin{array}{r}50 \cdot 8 \\
\pm 2 \cdot 3\end{array}$ \\
\hline $\begin{array}{l}\text { After } \\
\text { recovery }\end{array}$ & $4 \cdot 2$ & $\begin{array}{r}45 \cdot 8 \\
\pm I \cdot 4\end{array}$ & $\begin{array}{r}49 \cdot 1 \\
\pm I \cdot 9\end{array}$ & $\begin{array}{r}49 \cdot 5 \\
\pm x \cdot 7\end{array}$ & $\begin{array}{r}5 I \cdot 0 \\
\pm I \cdot 3\end{array}$ & $\begin{array}{r}52 \cdot 0 \\
\pm 1 \cdot 5\end{array}$ & $\begin{array}{r}50 \cdot 3 \\
\pm 1 \cdot 5\end{array}$ & $\begin{array}{r}49 \cdot 4 \\
\pm \mathrm{I} \cdot 8\end{array}$ & $\begin{array}{r}48 \cdot 7 \\
\pm 1 \cdot 7\end{array}$ \\
\hline
\end{tabular}

\section{RESULTS}

\section{Postprandial metabolic rates}

The mean 'standard' and postprandial metabolic rates of the twelve children on admission, during the phase of rapid growth and after recovery are summarized in Table 2. On admission, the 'standard' metabolic rates, expressed per $\mathrm{kg}$ body-weight, tended to be lower than those during and after recovery, but not significantly so $(t$ test applied to a paired comparison). 
After the test meal, metabolic rates increased and in most patients reached a maximum at $\mathrm{I} h$. This increase was small in the malnourished child, the mean postprandial metabolic rate at $\mathrm{I} h$ representing a $6.5 \%$ increase. In contrast, during recovery, when growth was rapid, the increase was four times as great, with a mean at $I h$ of $23.5 \%$.

After recovery the mean postprandial metabolic rate occupied an intermediate position, the increase at $\mathrm{I} h$ being $\mathrm{I} 2 \cdot 2 \%$. When growth rates were calculated it became apparent that five of the children were still gaining weight quite rapidly, at rates ranging from 5.7 to $10.3 \mathrm{~g} / \mathrm{kg}$ body-weight. $\mathrm{d}$. The remaining children were all gaining weight at rates of less than $4 \mathrm{~g} / \mathrm{kg}$ body-weight.d. The recovered children thus were separated into two groups and the percentage increases in postprandial metabolic rate were plotted as shown in Fig. I. Children who had recovered and whose weight had reached a plateau produced a modest increase in metabolic rate after a meal, very similar to the pattern found on admission. On the other hand, children who had recovered but who were still gaining weight rapidly had large increases, similar to those found during the recovery phase.

The change in metabolic rate after the meal was plotted for each child. The area under the curve was estimated by carefully dissecting the graph paper, which was always of the same type, and weighing the dissected curve. The areas under the curves were compared in the different groups and the results were as follows:

rapid growth $v$. admission $P<0.00$;

rapid growth $v$. recovered but still growing rapidly NS;

rapid growth $v$. recovered and 'plateaued' $P<0.00$;

recovered but still growing rapidly $v$. recovered and 'plateaued' $P<0.02$.

\section{Correlation between growth rate and the increase in postprandial metabolic rate}

Thirty-four measurements of postprandial metabolic rate were made on twenty-two children, whose rates of weight gain ranged from o to $18.9 \mathrm{~g} / \mathrm{kg}$ body-weight. $\mathrm{d}$. The percentage increases in postprandial metabolic rate were plotted for each test and the area under the curve was estimated as before. Fig. 2 shows the percentage increase in metabolic rate for the entire $\mathrm{r} \cdot 75 \mathrm{~h}$ after the meal, plotted against growth rate, and the corresponding regression line. The correlation coefficient is +0.90 , which is highly significant $(P<0.001)$.

\section{$R Q$}

Fig. 3 shows the mean RQ measured before and at 5 min intervals after the test meals in the twelve children at different times after admission to hospital. On admission the mean 'standard' $\mathrm{RQ}$, measured $4 \mathrm{~h}$ after the last meal, was 0.808 (SE $=0.019$ ). This was lower than the mean value found after recovery $(0.836, \mathrm{sE}=0.016, P=0.05)$. During rapid growth the mean 'standard' $\mathrm{RQ}$ was 0.886 ( $\mathrm{SE}=0.0 \mathrm{rr}$ ), which was significantly higher than it was on admission $(P<0.001)$, and it was also higher than the mean 'standard' RQ after recovery $(P<0.00 \mathrm{I})$. No difference in 'standard' $\mathrm{RQ}$ 
was found between recovered children who were still growing rapidly and those whose growth curve had reached a plateau.

In the newly admitted children the RQ after the test meal increased markedly, particularly during the first $I_{5} \mathrm{~min}$. In recovered children the $\mathrm{RQ}$ also rose, but more slowly, whereas that of rapidly growing children fell slightly. By $I h$ the $R Q$ were similar in all four groups.

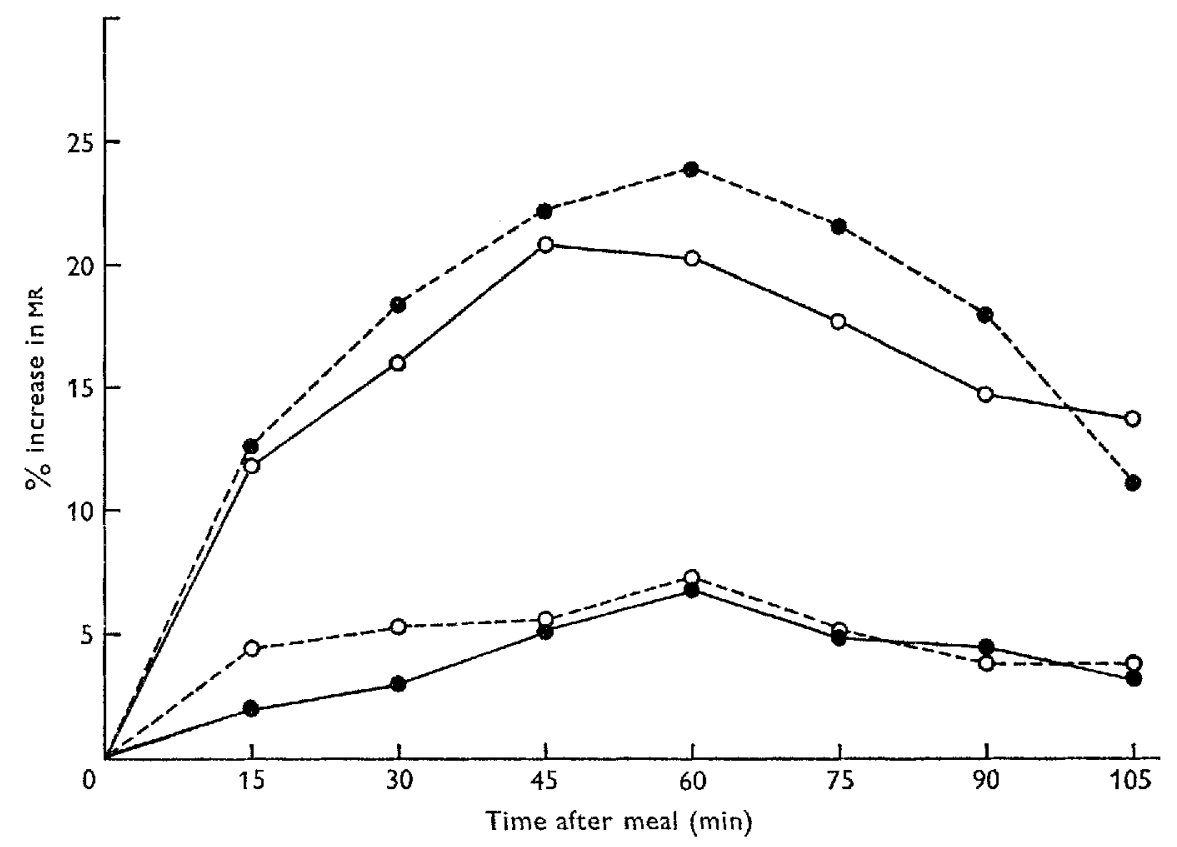

Fig. I. Changes in metabolic rate (MR) after a meal in four groups of children. nourished, on admission; -- , during rapid growth; $\mathrm{O}-\mathrm{O}$, recovered but still growing rapidly; $\mathrm{O}--\mathrm{O}$, recovered, normal growth rate resumed.

\section{DISCUSSION}

These results confirm our previous findings (Ashworth, rg69a) that the metabolic rate after a meal increases markedly during the phase of rapid 'catch-up' growth, whereas after recovery little increase is found provided growth rates are modest. Newly admitted malnourished children, who are presumed to have arrested growth, also have minimal increases in postprandial metabolism. An interesting aspect of the present study is the observation that children who continue to grow at fairly rapid rates after recovery persist in having sizeable increases in postprandial metabolic rate. Thus entirely different patterns of metabolism exist within children who are of similar nutritional status, who are given similar meals, but who are growing as different rates.

The results reported here are also consistent with those of Krieger (1966) for infants recovering from growth failure. From measurements of insensible water loss, 


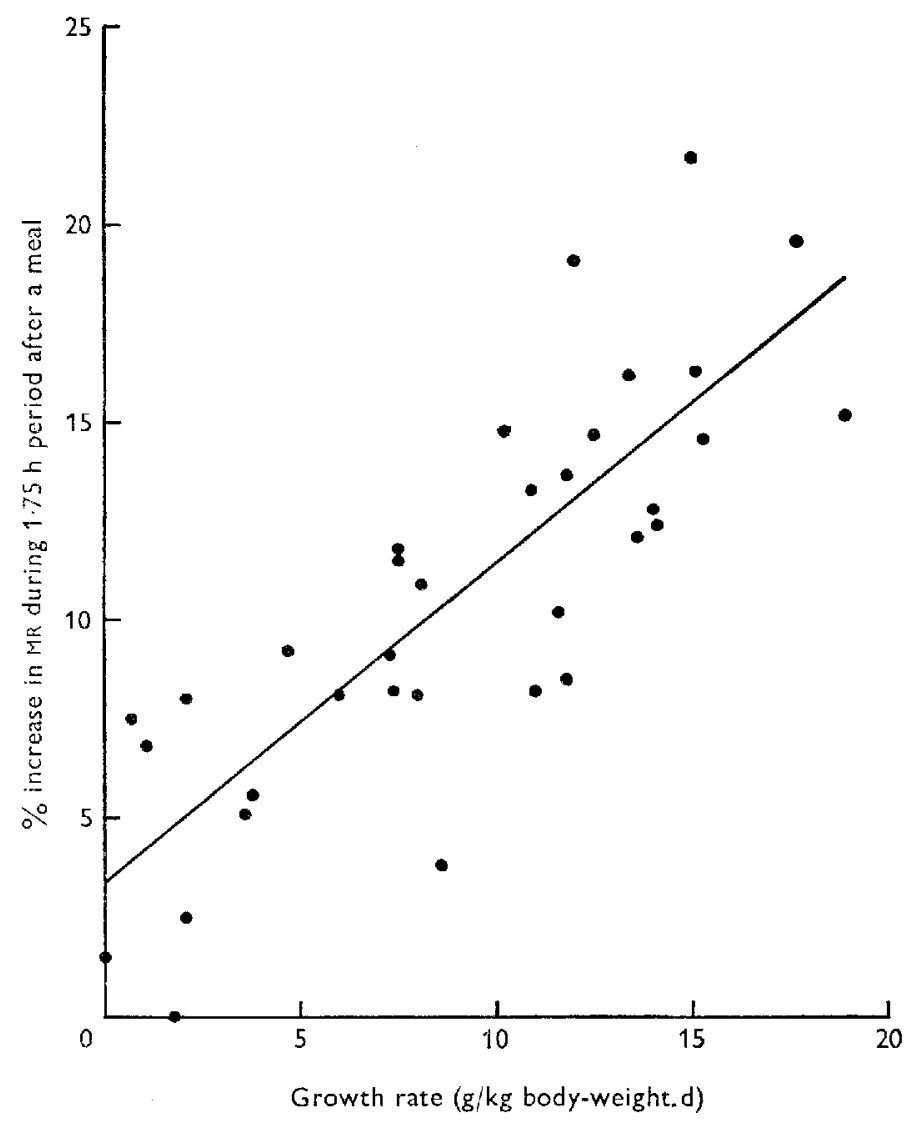

Fig. 2. Relationship between postprandial increase in metabolic rate (MR) and growth rate in twenty-two children (thirty-four measurements), and the fitted regression line.

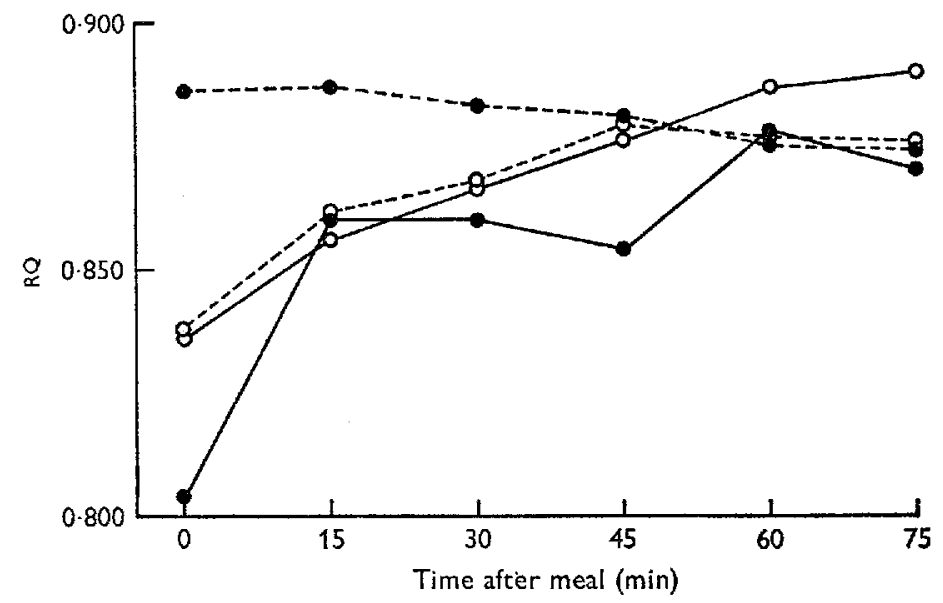

Fig. 3. Changes in respiratory quotient (RQ) after a meal in four groups of children. malnourished, on admission; - - , during rapid growth; $\mathrm{O}-\mathrm{O}$, recovered but still growing rapidly; $O--O$, recovered, normal growth rate resumed. 
Krieger determined metabolic rates $4 \mathrm{~h}$ and $\mathrm{I} 2 \mathrm{~h}$ after a regular meal. He found that there was very little difference on admission and after recovery between the two rates, but during recovery the standard $(4 \mathrm{~h})$ metabolic rate was considerably higher than the basal (i2 h) value. In a subsequent study, Krieger \& Whitten (I969) found that the difference between the $4 \mathrm{~h}$ and the $\mathrm{I} 2 \mathrm{~h}$ values correlated closely with growth rate.

We have now shown that during and after recovery a convincing relationship exists between growth rate and the magnitude of the increase in metabolic rate after a meal. This adds support to the theory advanced by Krieger (1966) and Ashworth ( $1969 a$ ) that the increase in postprandial metabolism under these conditions represents the energy cost of growth. It is of interest that in one child (C.E.) on whom daily studies were performed during the rst week after admission, the postprandial metabolic rate started to increase as the child began to gain weight.

During the phase of rapid growth the mean rate of weight gain in these children was $12.6 \mathrm{~g} / \mathrm{kg}$ body-weight.d. From Fig. 2 the increase in postprandial metabolism for this growth rate only accounts for $0.75 \mathrm{kcal}(3.14 \mathrm{~kJ}) / \mathrm{kg}$ body-weight. $2 \mathrm{~h}$. This is much less than would be expected from the published figures of Kielanowski \& Kotarbiniska (1969) for the energy cost of tissue synthesis. It is possible that the postprandial metabolic rate increase represents protein synthesis in the liver, while protein synthesis in muscle continues at a steady rate. This is supported by the results of Watanabe, Potter \& Pitot (1968), who showed that liver protein synthesis responds rapidly to fluctuations in amino acid concentrations in portal blood. Millward (1970) found that the total rate of protein turnover in fasted rat muscle was rather more than twice that in liver. However, no information is available with regard to postprandial fluctuations in muscle protein synthesis, so it remains to be determined whether this concept is adequate to explain the facts.

It is perhaps surprising that the correlation between growth rate and the increase in postprandial metabolic rate shown in Fig. 2 was so high, since growth rates were based on measurements made during the week preceding the test, and during this time the quantity of milk that the children were receiving was not necessarily the same as the test meal. Furthermore, widely differing increases in postprandial metabolic rates were observed in these children, although they had been given, on a weight basis, identical amounts of protein and calories. These findings are at variance with the classical theory of specific dynamic action from which one would expect the size of the increase in postprandial metabolic rate to be determined chiefly by the protein content of the meal. The findings are also at variance with those reported by Miller $\&$ Parsonage (1971), who found a correlation between energy intake and postprandial metabolism in rats.

It may be that children who are gaining weight at high rates develop a capacity for very rapid tissue synthesis following a meal, which may not necessarily be related to the size of a particular meal.

The high preprandial Re found during 'catch-up' growth probably reflects the deposition of fat formed from dietary carbohydrate in the presence of the large excess of dietary calories. Following the meal the Re fell slightly. This indicates that the increment in fat-derived calories was greater than that of carbohydrate-derived 
calories. The increased use of fat calories under these circumstances may be explained by the high energy cost of new tissue synthesis.

Newly admitted malnourished children show little increase in postprandial metabolic rate. Two simple explanations which could account for this are (I) that the test meal is poorly absorbed, or (2) that tissue synthesis does not occur in these children despite the provision of adequate food.

The evidence available in support of the former is slight. Waterlow \& Wills (1960) demonstrated that nitrogen absorption and retention are high initially in children admitted to this Unit, and amino acids are also well absorbed (R. J. Neale \& A. Nicholson, personal communication). Lactose intolerance is unlikely since none of the children had diarrhoea. We have measured faecal calorie excretion in two malnourished children given the test diet within $7 \mathrm{~d}$ of admission, and $92.4 \%$ and $86 \%$ of the calories were absorbed. These values are within the range $(73 \cdot \mathbf{r}-97 \cdot 8 \%)$ reported by Fleming \& Hutchison (1924) for healthy children. Good absorption of fat has been reported in Ugandan children with kwashiorkor (McCance, Rutishauser \& Boozer, I970).

In many malnourished children there is a lag phase before weight gain is observed; in some children this may be due to diarrhoea, fever, vomiting or the presence of infection. Also food intakes tend to be low initially. On the other hand, new tissue synthesis may be masked by loss of excess body water. In this study none of the children had diarrhoea, fever, vomiting or infection, and the test meals were more than adequate. It is possible, therefore, that tissue synthesis cannot begin until gross electrolyte disturbances have been corrected and enzyme levels readjusted. If growth indeed does not occur, the destination of the excess calories must be explained, since the test meal provides approximately twice the maintenance calorie requirement, and rapid weight gains are achieved later in the same children with this regimen.

Hypoglycaemia is not uncommon in children with malnutrition, indicating that glycogen reserves are small. Fasting blood levels of fatty acids are high (Lewis, Hansen, Wittman, Krut \& Stewart, r964) and in our studies the RQ on admission was low before the test meal, indicating that body fat was being catabolized to provide energy. After a meal the RQ rose steeply and there appeared to be a marked shift to carbohydrate metabolism. If the carbohydrate fraction of the meal is converted into glycogen, and the fat (which supplies most of the calories in this diet) is channelled back into the fat stores, relatively little energy would be required.

Children who had recovered and whose weight had reached a plateau produced a modest increase in postprandial metabolic rate, similar to the pattern on admission and, although the situations are clearly different, the same question of disposal of excess calories arises. In these circumstances it is unlikely that malabsorption occurs. If the size of the increase in postprandial metabolic rate is related to tissue synthesis, then we must conclude that in these children little synthesis of normal tissue is taking place. After the test meal the RQ rose and there was a shift away from fat catabolism. More than half the calories in the test meal come from fat and the only explanation that we can offer for the disposal of excess calories is by fat storage. If this is so, one would expect the children to gain weight nevertheless. This is not at variance with our results 
since the test meal was on average $14 \%$ greater than the food intakes measured during the week before the study, and greater weight gains presumably would have occurred if this level of intake had been maintained by force-feeding.

In children who had recovered but were still growing rapidly, the pattern of RQ change after the meal was different from that seen during the period of rapid growth, although both groups had large increases in postprandial metabolic rate. It is possible that this is the result of deposition of new adipose tissue in addition to the synthesis of 'balanced' tissue. In a previous study (Ashworth, $1969 b$ ) measurements of body composition indicated that when children reached their expected weight for height, the percentage body fat increased.

In summary, we believe that the increase in postprandial metabolic rate is correlated with tissue synthesis with a high energy requirement. Little increase in postprandial metabolism occurs in children who are not growing, whether newly admitted or recovered; in such patients the test meal provides an excess of calories and the most likely route for disposing of this excess is by diverting dietary fat to the fat stores - a process which requires little energy. Children who are growing rapidly have large increases in postprandial metabolic rate and during 'catch-up' growth dietary fat becomes an important energy source after a meal, whereas recovered, growing children utilize more carbohydrate. This difference may result from changes in the relative amounts of 'normal' tissue and adipose tissue being laid down.

We wish to thank Professor J. C. Waterlow, Dr G. A. O. Alleyne and Dr D. Picou for their valuable assistance in the preparation of this manuscript, and also the nursing staff for supervising the children in the ward.

\section{REFERENCES}

Ashworth, A. (1969a). Nature, Lond. 223, 407.

Ashworth, A. (1969b), Br. F. Nutr. 23, 835 .

Coleman, W. \& DuBois, E. F. (I91 5). Archs intern. Med. 15, 887.

Fleming, G. B. \& Hutchison, H. S. (1924). Q. $7 l$ Med. 17, 339.

Kielanowski, J. \& Kotarbińska, M. (1969). Proc, int. Congr. Nutr. vir. Prague p. K-I8.

Krieger, I. (1966). Pediatrics $\mathbf{3}^{8}, 63$.

Krieger, I. \& Whitten, C. F. (1969). F. Pediat. 75, 374.

Lewis, B., Hansen, J. D. L., Wittman, W., Krut, L. H. \& Stewart, F. (I964). Am. J. clin. Nutr. I5, 161. McCance, R. A., Rutishauser, I. H. E. \& Boozer, C. N. (r97o). Archs Dis. Childh. 45, 410.

Miller, D. S., Mumford, P. \& Stock, M. J. (1967). Am. F. clin. Nutr. 20, 1223.

Miller, D. S. \& Parsonage, S. R. (1971). Proc. Nutr. Soc. 30, 76 A.

Millward, D. J. (1970). Clin. Sci. 39, 591.

Mount, L. E. (1969). Br. F. Nutr. 23, 407.

Nelson, W. E., Vaughan, V. C. \& McKay, R. J. (1969). Textbook of Pediatrics 9th ed. Philadelphia and London: W. B. Saunders Co.

Passmore, R. \& Ritchie, F. J. (1957). Br. $\mathcal{F . ~ N u t r . ~ I I , ~} 79$.

Watanabe, M., Potter, V. R. \& Pitot, H. C. (1968). F. Nutr. 95, 207.

Waterlow, J. C. \& Wills, V. G. (1960). Br. F. Nutr. 14, I83. 